REVIEW

\title{
Clinical Conditions and Predictive Markers of Non-Dipper Profile in Hypertensive Patients
}

\author{
Ioan Tilea ${ }^{1}$, Dorina Petra²* Elena Ardeleanu³ ${ }^{3}$ Adina Hutanu4 ${ }^{4}$, Andreea Varga ${ }^{1}$ \\ 1. Family Medicine, Dept. M3 - Internal Medicine, Faculty of Medicine, University of Medicine and Pharmacy Tirgu Mures, Romania \\ 2. Internal Medicine I, Dept. M3 - Internal Medicine, Faculty of Medicine, University of Medicine and Pharmacy Tirgu Mures, Romania \\ 3. Family Medicine, Dept. XVI - Balneology, Medical Rehabilitation and Rheumatology, Faculty of Medicine, University of Medicine and Pharmacy "Victor \\ Babes" Timisoara, Romania \\ 4. CCAMF, University of Medicine and Pharmacy Tîrgu Mureș, Romania Department of Laboratory Medicine, University of Medicine and Pharmacy Tîrgu \\ Mures, Romania
}

Hypertension remains one of the primary causes of premature cardiovascular mortality representing a major independent risk factor. The importance of ambulatory blood pressure monitoring in clinical evaluation of hypertensive patients, beyond diagnosis, is the identification of circadian dipping/non-dipping profile. The non-dipper pattern in hypertensive and normotensive patients is associated with significant target organ damage and worse outcomes, as an increased cardiovascular risk condition. Non-dipping pattern has been found to be associated with specific clinical conditions. Obesity, diabetes mellitus, metabolic syndrome, obstructive sleep apnea syndrome, chronic kidney disease, autonomic and baroreflex dysfunctions, salt sensitivity, hormonal changes, gender and age were extensively studied. Research efforts are focused on recognizing and exploring predictive markers of abnormal blood pressure circadian pattern. Previous studies acknowledge that red cell distribution width, mean platelet volume, fibrinogen level, C-reactive protein, serum uric acid and gamma-glutamyltransferase, are independently significant and positive associated to non-dipping pattern. Moreover, research on new biomarkers are conducted: Chitinase 3-Like-Protein 1, atrial and B-type natriuretic peptide, brain-derived neurotrophic factor, chemerin, sphingomyelin and the G972R polymorphism of the insulin receptor substrate-1 gene. This review summarizes the current knowledge of different clinical conditions and biomarkers associated with the non-dipper profile in hypertensive patients.

Keywords: systemic hypertension, non-dipper profile, cardiovascular risk, clinical conditions, predictive markers

Received 24 December 2017 / Accepted 05 February 2018

\section{Introduction}

Hypertension was identified as a main preventable cause of morbidity and premature mortality worldwide, $31.1 \%$ adults suffering from this condition. Hypertension prevalence displays a significant difference between high-income and low-and middle-income countries. [1]

Different approaches to treatment, awareness and control along with additional increase of life expectancy, grant the emerging incidence of hypertension. [2]

In 2012 hypertension prevalence in Romanian population was $40.4 \%$ as reported by SEPHAR II survey. $85 \%$ patients were taking antihypertensive treatment and adequate control was obtained in a quarter. [3]

SEPHAR III survey (2016) results revealed an ascending prevalence, with $19.1 \%$ newly diagnosed hypertensive patients out of $45.1 \%$ total prevalence. [4]

Ambulatory blood pressure monitoring (ABPM) is the recommended standard method in accurate diagnosis of true high blood pressure (BP), systolic and diastolic values along with all particular aspects of the circadian BP variation. [5,6]

The dipper profile is defined by at least $10 \%$ decline, but not more than $20 \%$ in systolic and/or diastolic BP value during the night-time, compared to daytime. The term non-dipper refers to patients whose blood pressure does not exhibit these variations. [6] Non-dipper hypertensive patients manifest an increased mortality risk, cardiac and extracardiac morbidity. $[7,8]$

Possible underlying mechanisms of non-dipper profile were explored in a multitude of studies conducted over the years, identifying clinical conditions linked to disturbances of 24-h systolic and/or diastolic BP variations. [9]

Complex mechanisms originating in endocrine, renal, neural, and vascular areas are involved in the pathogenesis of arterial hypertension and its circadian variability. Poor sleep quality and the absence of physical exercise during the day, are likely affecting the abnormal night-to-day BP ratio. (Table I)

Significant target organ damage (TOD) such as left ventricular hypertrophy, stroke, changes in carotid wall thickness and atherosclerotic plaques, along with renal and ocular damage were recognized in non-dipper hypertensive patients. [7,8,21,22]

Non-dipper profile is not a static marker of the cardiovascular status. Hypertension pattern identification and therapeutic interventions can improve patient prognosis. [23-25]

This review summarizes the current knowledge of different clinical conditions and biomarkers associated with the non-dipper profile in hypertensive patients. 
Table I. Conditions associated with non-dipping pattern

\begin{tabular}{ll}
\hline Endocrine system & Hypo/Hyperthyroidism [9,10] \\
disorders & Primary hyperparathyroidism [11] \\
& Aldosteronism [9] \\
& Cushing syndrome [9] \\
& Pheochromocytoma [10] \\
& Hypopituitarism [12] \\
& Impaired nocturnal melatonin secretion [13] \\
& Acromegaly [14] \\
& Chronic kidney disease [10] \\
& Renal transplantation [15] \\
Renal dysfunction & Unilateral nephrectomy [16] \\
& Autonomic failure \\
Autonomic nervous & Orthostatic hypotension [17, 18] \\
system dysfunction & Obstructive sleep apnea [10] \\
Sleep disturbances & Stress disorders [19] \\
& Impaired sleep quality [20] \\
& Obesity \\
Other [10] & Diabetes mellitus \\
& Metabolic syndrome \\
& Salt sensitivity \\
& Age, gender
\end{tabular}

\section{Autonomic nervous system}

Neural mechanisms are believed to play an important role in non-dipper hypertension profile.

Increased autonomic nervous system activity is involved in triggering and maintaining high BP. Different techniques were used to measure sympathetic nervous system (SNS) activity: electrophysiological studies and measurement of norepinephrine neurotransmitter values in plasma and urine samples. [26]

Dauphinot and colab. report that patients with impaired autonomic nervous system activity present an insufficient decrease in nocturnal BP. [27] Non-dipper hypertensive patients have low circulating norepinephrine and higher peripheral vascular resistance compared to dippers. [28]. Grassi et al. provide evidence that in arterial hypertension is a close correlation between the sympathetic activation degree and the magnitude of nocturnal decrease in systolic or diastolic BP. [10,29]

\section{Orthostatic hypotension}

Orthostatic hypotension is a relatively common and multifactorial disorder, often secondary to autonomic dysfunction. BP variation related to posture was associated to non-dipper pattern in female gender taking at least 2 antihypertensive drugs. Orthostatic hypotension could be a marker of non-dipper profile. [30]

Alquadan et al. demonstrated that postprandial hypotension and cardiac rhythm variability computed on ABPM are potent predictors of autonomic dysfunction in routine clinical practice. [31] Frequently, patients with orthostatic hypotension may develop non-dipper hypertension profile, which is a treatment challenge for physicians. [18]

\section{Obesity}

Compared to normal weight, obesity is responsible for five times increase in hypertension incidence. [32] In the complex obesity-associated hypertension process, activation of renin-angiotensin-aldosterone system (RAAS), endothelial and adipose tissue dysfunction and the sympathetic nervous system (SNS) stimulation, represents the underlying mechanisms. [33-35]

Through pathological activation of RAAS, in visceral adipocytes renin-angiotensin-aldosterone metabolites involved in BP regulation are released: angiotensinogen, renin and renin receptor, angiotensin-converting enzyme, angiotensin I type and angiotensin II receptors. Angiotensinogen via angiotensin II induce hypertension by systemic vasoconstriction, sodium and fluid balance, and stimulates aldosterone secretion. [33]

The role of metabolic dysregulation in obesity-associated hypertension implies the malfunction of connection between microvascular and perivascular adipose tissue inflammation to adipokine and neuropeptides synthesis. Leptin, resistin, adiponectin, visfatin, TNF- $\alpha$, IL-6, MCP-1 and IL-1 further disturb the sympathetic activity and influence the tight link with insulin resistance. Both mechanisms are responsible in hypertension development. [33,36,37]

Different studies observed that basic mechanisms of obesity-associated hypertension are very much alike to mechanisms determinants of non-dipping pattern of hypertension. [10,38-40]

Ayukusuma et al. in a small study investigated the serum level of interleukin-6 (IL-6), as a key mediator of mechanism between hypertension and inflammation. Performed on forty-eight hypertensive patients, study concluded that IL-6 serum level did not differ among dipper and nondipper hypertensive patients. [41]

\section{Diabetes mellitus and metabolic syndrome}

Decline of physiological mechanisms in hypertensive patients with diabetes mellitus or metabolic syndrome (MS), are considered to be also responsible for the non-dipper hypertension pattern: insulin resistance (anti-diuretic action of insulin), exaggerated response to internal vasoconstrictors, surge of SNS activity, damage endothelium-vasodilatation dependant and results of thickening in vascular smooth muscle. [10]

Duggal and colab. showed that $46 \%$ of hypertensive patients with type 2 diabetes had a non-dipper profile. This profile is associated to higher prevalence of microalbuminuria and advanced age. Authors emphasize the importance of BP profile identification and early specific treatment in particular patients, stratified as patients at increased risk of cardiovascular and renal mortality and morbidity. [42]

BP pattern of hypertensive patients taking antihypertensive medication and presenting metabolic syndrome, were also studied by Tartan et al. using the MS-Score. A predictive role of high MS-Score for the non-dipping pattern of BP was proved. [43]

In addition, abdominal obesity associated with increased level of uric acid in patients with MS was closely related to non-dipper blood pressure profile as it was suggested by Tutal et colab. [44] 
Metabolic syndrome pathophysiology that underlies the increase of arterial stiffness in non-dipper patients, determine aortic function damage, through exposer of the aortic wall to additional pressure load. Non-dipper obese hypertensive patients had an enlarged thoracic aortic diameter compared to dipper patients. [45]

Karaagac et al. demonstrated that for non-dipper hypertensive patients associating MS, specific 12-lead electrocardiogram parameters are valuable for assessing the increased cardiovascular morbidity and mortality risk. The interval between the peak (Tp) and the end $(\mathrm{Te})$ of $\mathrm{T}$ wave, $\mathrm{Tp}$ Te interval, is an index of total dispersion of myocardial repolarization. Combined with Tp-Te/QT ratio (QT- extension of the time between the beginning of the $\mathrm{Q}$ wave, and the intersecting descending part of $T$ wave to isoelectric line) and Tp-Te/QTc ratio (QTc- corrected QT) these markers of potential ventricular arrhythmias were significantly higher and very strong associated to the non-dippers with metabolic syndrome. [46]

\section{Obstructive sleep apnea}

Obstructive sleep apnea (OSA) syndrome severity directly influence the non-dipping pattern. Despite mild severity of OSA, transient hypoxemia and hypercapnia caused by recurrent episodes of apnea, trigger changes in SNS activity and disrupt night sleep. [10] An increased OSA severity reduces the dipping pattern, augmenting the non-dipper number of OSA patients. [47]

Normotensive and hypertensive OSA patients are more affected by impaired nocturnal BP decrease than regular normotensive or hypertensive patients. [48] Apnea-hypopnea index has a significant association to non-dipper profile and no association to age or body mass index. [49]

Wolf et al. summarized the potential pathways of causative relation of OSA to non-dipper pattern: endothelium damage, oxidative stress, high levels of plasma asymmetric dimethyl arginine concentration and elevated L-selectin, ICAM-1 (intercellular adhesion molecule-1) and VCAM1 (vascular cell adhesion molecule-1). [50]

In obese patients with MS and OSA syndrome treatment with continuous positive airways pressure, upper airway surgery or stimulation, can improve BP circadian variations and reduces cardiovascular risk. [ 47,51$]$

\section{Hormones}

Routledge et al. analysed 47 menopausal women ABPM recordings. Non-dipper female patients $(34 \%)$ were older and had lower stress scores compared to dipper participants. [52]

Research in perimenopausal hypertensive women reported $61.5 \%$ non-dipper profile in a sample of 130 participating women. Non-dipper profile in perimenopausal women more often associates obesity, postural hypotension, microalbuminuria, and elevated glycosylated haemoglobin, fibrinogen, C-reactive protein. [53]

\section{Thyroid}

Systolic and diastolic BP were investigated in relation to serum thyrotropin (TSH), in patients presenting elevated TSH levels with typical disease manifestation or subclinical form of hypothyroidism. Within normal TSH limits, a positive association was found between both, systolic $(>160 \mathrm{~mm} \mathrm{Hg})$ and diastolic $(>95 \mathrm{~mm} \mathrm{Hg})$ hypertension, and TSH serum. [54]

Nevertheless, a recent study presented results supporting the theory that hypertensive patients with subclinical hypothyroidism more frequently experience a diastolic non-dipper profile. [55]

Possible pathway of determining the non-dipper pattern in hypothyroidism is the result of increase vascular resistance under SNS influence. [10]

Concerning other thyroid hormones, an independent association of non-dipping pattern to low level of free triiodothyronine was reported in a study by Kanbay et al. investigating patients with no thyroid hormone disorder. [56]

\section{Parathyroid hormone}

Kanbay et colab. reported that non-dipper pattern in hypertensive patients is significantly associated to higher levels of phosphate, Calcium x Phosphorus product, and parathyroid hormone level. [57]

\section{Chronic kidney disease}

Prospective and cross-sectional studies in chronic kidney disease $(\mathrm{CKD})$ patients have demonstrated changes in 24-h BP pattern that may support kidney function worsening. Mechanisms involved include RAAS provocation, endothelin activation, inflammation, altered baroreceptor sensitivity and SNS activity. [58]

CKD patients have a higher prevalence of non-dipping pattern and elevated mean systolic overnight BP, results shown by monitoring 1805 patients in Ancona Hypertension Centre, Italy. [59] Aggregate data confirm that personalised therapy (selection of drugs, dosage and chronotherapy) is needed in order to prevent long-term cardiovascular events and TOD in abnormal BP variations of CKD hypertensive patients. $[58,59]$

Non-dipper pattern is a negative determinant in the nephropathy evolution in type 1diabetes patients and a risk factor for microalbuminuria evolution. [60]

In renal transplantation patients, assessing the Doppler renal resistive index proved to be a strong predictor for non-dipper profile. [61] Presence of abnormal circadian $\mathrm{BP}$ variation at one year in kidney transplantation patients, increases the risk of transplanted kidney failure in the next 3-4 years. [62]

Non-dippers with reduced left ventricular ejection fraction (LVEF) have increased incidence of renal and cardiovascular worse outcomes, compared to dippers. In non-diabetic patients affected by decreased glomerular filtration 
rate and progression of renal disease, 24-h ABPM and LVEF can be used as prognostic markers. [63]

Extended research is also conducted for identification of potential pathways of salt-induced non-dipper profile in hypertensive patients.

Data derived from a study conducted on 115 young never treated hypertensives patients, suggested that G972R insulin receptor substrate-1 gene (IRS-1) polymorphism, is associated with insulin resistance, salt sensitivity and nondipper hypertension. [64] Heterozygous carriers exposed to high salt diet develop non-dipper hypertensive profile.

Decrease in night-time BP was identified in groups of salt sensitive hypertensive patients with sodium intake restriction. [65]
Elevated concentrations of plasma norepinephrine, CKD with attenuated inhibition of RAAS, impaired renal sodium excretion and genetic factors were recognized as responsible for salt-induced non-dipper hypertensive profiles. [66]

\section{Therapeutic strategy}

Current guidelines on treatment and management of hypertension do not recommend personalised treatment in dipper and non-dipper hypertensive patients. [6]

However, the 2016 European Guideline on cardiovascular disease prevention in clinical practice, indicates the assessment of dipping pattern or suspicion of non-dipping in CKD or diabetes mellitus patients or OSA patients. [67]

Table II. Current laboratory predictive biomarkers of non-dipper hypertension profile

\begin{tabular}{|c|c|c|c|c|}
\hline Author, year & $\begin{array}{c}\text { Participant } \\
\text { number }\end{array}$ & Biomarker & Results in non-dipper subjects & Study conclusion \\
\hline \multirow[b]{3}{*}{ Tosu, 2014. [74] } & \multirow[b]{3}{*}{120} & Uric acid & Significantly higher levels compared to dip- & \multirow{3}{*}{$\begin{array}{l}\text { In non-dippers, increased inflammatory markers can be } \\
\text { the reason of advanced end-organ failure in conjunction } \\
\text { with cardiovascular morbidity and mortality. }\end{array}$} \\
\hline & & C-reactive protein & pers/control group $(p<0.05)$ & \\
\hline & & $\begin{array}{l}\text { Red blood cell } \\
\text { distribution width } \\
\text { (RDW) }\end{array}$ & $\begin{array}{l}\text { Significantly higher than dippers/normoten- } \\
\text { sives } \\
\qquad(p<0.05)\end{array}$ & \\
\hline \multirow{2}{*}{$\begin{array}{l}\text { Buyukkaya, } 2016 . \\
\text { [75] }\end{array}$} & \multirow{2}{*}{170} & RDW & $\begin{array}{l}\text { Higher values compared to dippers } \\
14.5 \pm 0.87 \text { vs. } 12.7 \pm 0.66, p<0.001\end{array}$ & \multirow{2}{*}{$\begin{array}{c}\text { High values of commonly hematological element (RDW) } \\
\text { may be linked to inflammatory state, in normotensive and } \\
\text { hypertensive non-dipper patients. }\end{array}$} \\
\hline & & hs-CRP & $\begin{array}{c}\text { Higher hs-CRP levels } \\
0.99 \pm 0.52 \text { vs. } 0.63 \pm 0.43, \mathrm{p}<0.001\end{array}$ & \\
\hline \multirow{2}{*}{ Kaya, 2010. [76] } & \multirow{2}{*}{126} & $\begin{array}{l}\text { Mean platelet } \\
\text { volume (MPV) }\end{array}$ & $\begin{array}{l}\text { Higher levels compared to normotensives } \\
\text { and dippers } \\
9.72+/-0.52 \mathrm{fl} \text { vs } 8.92+/-0.42 \mathrm{fl} \text { and } 9.38+/- \\
0.33 \mathrm{fl}, \mathrm{p}<0.05\end{array}$ & \multirow{2}{*}{$\begin{array}{l}\text { Inflammatory activity and raised platelet activation pat- } \\
\text { tern are present in non-dipper hypertensive patients, } \\
\text { increasing the atherosclerotic risk. }\end{array}$} \\
\hline & & hs-CRP & $\begin{array}{c}\text { Significantly raised compared to normoten- } \\
\text { sives and dippers } \\
4.9+/-1.7 \mathrm{mg} / \mathrm{l} \text { vs } 2.7+/-0.8 \mathrm{mg} / \mathrm{l} \text { and } 3.8+/- \\
1.5 \mathrm{mg} / \mathrm{l}, \mathrm{p}<0.05\end{array}$ & \\
\hline $\begin{array}{l}\text { Ortakoyluoglu, } \\
\text { 2016. [77] }\end{array}$ & 171 & $\begin{array}{l}\text { Gamma-glutamyl- } \\
\text { transferase } \\
\text { (GGT) }\end{array}$ & $\begin{array}{l}\text { Significant increased versus dipper } \\
36.2 \pm 13.8 \text { vs } 20.5 \pm 8.8 \mathrm{U} / \mathrm{L}, \mathrm{p}=0.03\end{array}$ & $\begin{array}{l}\text { GGT positively associated to non-dipper profile; nega- } \\
\text { tively related to night-to-day BP variation. }\end{array}$ \\
\hline \multirow{2}{*}{ Tabara, 2016. [78] } & \multirow{2}{*}{1020} & BNP plasma & $\begin{array}{l}\text { Positively related to circadian BP variations } \\
\qquad(p<0.001)\end{array}$ & \multirow{2}{*}{$\begin{array}{c}\text { Mild elevation of BNP plasma level identified as marker } \\
\text { of atypical BP circadian variation along with abnormal } \\
\text { pattern of nocturnal BP. }\end{array}$} \\
\hline & & $\begin{array}{l}\text { Oxygen desatura- } \\
\text { tion }(\mathrm{SpO} 2)\end{array}$ & $\begin{array}{l}\text { Positive association } \\
\text { OR: } 1.04, p=0.001\end{array}$ & \\
\hline Bakirci, 2015. [79] & 80 & YKL-40 levels & $\begin{array}{l}\text { Significantly greater compared to dippers } \\
183.1 \pm 59.1 \text { versus } 125.9 \pm 50.3 \mathrm{pg} / \mathrm{mL} \\
\mathrm{p}<0.001\end{array}$ & $\begin{array}{l}\text { Higher level of YKL-40 serum, hs-CRP together with } \\
\text { epicardial adipose tissue thickness were independently } \\
\text { markers of non-dipper pattern; it can constitute an } \\
\text { improved prediction tool for prevention and immediately } \\
\text { treatment of high risk non-dipper induced cardiovascular } \\
\text { outcome. }\end{array}$ \\
\hline Ji, 2017. [80] & 60 & $\begin{array}{l}\text { CD4+ effector T } \\
\text { (Teff) cells: Th1, } \\
\text { Th2, Th17 }\end{array}$ & $\begin{array}{l}\text { Th1 and Th17 notably higher compared to } \\
\text { the dippers } \\
\text { Th2 level significantly higher in dippers when } \\
\text { compared to non-dippers }\end{array}$ & $\begin{array}{l}\text { Th1 and Th17 subsets response were independently } \\
\text { associated with the non-dipper pattern. } \\
\text { TOD, hypertension prevention and treatment could ben- } \\
\text { efit out of adjusting the CD4+ effector T cells. }\end{array}$ \\
\hline Kadoya, 2014. [81] & 250 & Plasma BDNF & $\begin{array}{l}\text { Intermediate value compared to highest value } \\
\text { determined in reverse-dippers }\end{array}$ & $\begin{array}{l}\text { Connection between autonomic nervous system activity, } \\
\text { evaluated through BDNF plasma level, with abnormal BP } \\
\text { circadian pattern. }\end{array}$ \\
\hline Meric, 2014. [82] & 90 & $\begin{array}{l}\text { Chemerin (tazaro- } \\
\text { tene-induced gene } \\
2 \text { protein-TIG2) }\end{array}$ & $\begin{array}{c}\text { Higher levels } \\
219.7 \pm 16.3 \text { vs. } 182.4 \pm 21.4 \mathrm{ng} / \mathrm{ml} \text {-dipper; } \\
p<0.001 \\
219.7 \pm 16.3 \text { vs. } 85.4 \pm 38.1 \mathrm{ng} / \mathrm{ml} \text {-normoten- } \\
\text { sive; } p<0.001\end{array}$ & $\begin{array}{l}\text { By determining the chemerin level in non-dipper hyper- } \\
\text { tensives, clinical decision can be improved in high risk } \\
\text { hypertensive patients. Results reinforced the inflamma- } \\
\text { tion role in pathophysiology of high BP. }\end{array}$ \\
\hline Zheng, 2014. [83] & 116 & Sphingomyelin & $\begin{array}{l}\text { Significance of systolic and diastolic BP night } \\
\text { decline was negatively correlated to plasma } \\
\text { SM level; } r=-0.42, p<0.01 \text { for systolic BP and } \\
r=-0.31, p<0.01 \text { for diastolic BP }\end{array}$ & $\begin{array}{l}\text { SM levels assessment may be applied in detection of } \\
\text { high risk cardiovascular patients, linked to non-dipper } \\
\text { pattern. }\end{array}$ \\
\hline \multirow[b]{2}{*}{ Cayli, 2013. [84] } & \multirow[b]{2}{*}{317} & Serum hs-cTnT & $\begin{array}{l}\text { Absolute predictor for non-dipper pattern } \\
\text { OR:1.409; } 95 \% \mathrm{Cl}, 1.276-1.556 ; \mathrm{p}<0.001\end{array}$ & \multirow{2}{*}{$\begin{array}{l}\text { Serum hs-cTnT and NT-proBNP value demonstrate } \\
\text { autonomous prediction for non-dipper profile in hyperten- } \\
\text { sive patients; serum hs-cTnT values are related to night } \\
\text { time systolic BP. } \\
\text { Newly diagnosed hypertensive patients, can benefit from } \\
\text { the potency of high sensitivity cardiac troponin T marker. }\end{array}$} \\
\hline & & NT-proBNP & $\begin{array}{l}\text { Independent marker of non-dipper pattern; } \\
\text { OR:1.012; } 95 \% \mathrm{Cl}, 1.005-1.020 ; \mathrm{p}=0.001\end{array}$ & \\
\hline
\end{tabular}


Nevertheless, treatment strategies based on dipper/nondipper status is an emerging novel concept for high-risk hypertensive patients. Recent studies contribute with close supporting evidence for personalized treatment approach in the non-dipper BP pattern. [68]

For the non-dippers, initiation or treatment adjustment along with choronotherapy, would determine highest benefit of antihypertensive therapy. Reducing the number of the non-dipping hypertensive patients will ensure longterm protection over cardiovascular events in patients presenting TOD, insulin resistance and increased proteinuria and fibrinogen levels. [69]

Bedtime administration of novel calcium channel blockers (barnidipine, cilnidipine) prove to restore normal dipping profile in most of OSA /non-OSA hypertensive patients. [24,25]

Kario et al. showed that administration of an alphaadrenergic blocker (doxazosin) at bedtime reduced blood pressure overnight in non-dipper pattern. [70]

In a systematic review conducted by Wang on $3732 \mathrm{pa}-$ tients, chronotherapy could invert non-dipper profile in hypertensive CKD subjects with no significant disparities for cardiovascular and all-cause mortality. [71]

In CKD hypertensive patients, bedtime valsartan administration in non-dippers provided renal protection by slowly decreasing the glomerular filtration rate and low 24 hours proteinuria. A better protection of the target organs was computed. [72] Diuretic therapy or salt restriction in CKD patients, restore the dipper pattern by normalising sodium excretion. [73]

Research efforts are focused on the detection of dipper/ non-dipper profile predictive markers. (Table II)

\section{Conclusions}

At present, available data support the evidence of certain clinical conditions related to non-dipper pattern.

Confirming the circadian BP variation with specific night-to-day BP ratio, is appropriate to investigate possible secondary causes of high BP, medication adjustment (dosage and chronotherapy) along with therapeutic drug and response monitoring. Antihypertensive therapeutic approach dependent on dipper/non-dipper profile represents an innovative, advanced concept aimed to maximize treatment response in high risk hypertensive patients.

Further studies are needed to reinforce the clear position of circadian blood pressure profile in practical aspects of hypertension.

\section{Conflict of interest}

None to declare.

\section{Acknowledgements}

This paper was partially supported by the University of Medicine and Pharmacy of Tirgu Mures and SC NOVAVITA HOSPITAL SA Tirgu Mures, Internal Research Grant 6849/15.06.2015.

\section{References}

1. Mills KT, Bundy JD, Kelly TN, et al - Global disparities of hypertension prevalence and control a systematic analysis of population - based studies from 90 countries. Circulation. 2016;134(6):441-450.

2. Lloyd-Sherlock P, Beard J, Minicuci N, Ebrahim S, Chatterji S - Hypertension among older adults in low- and middle-income countries: prevalence, awareness and control. International Journal of Epidemiology, 2014;43(1):116-128.

3. Dorobantu M, Onciul S, Darabont R, et al - Arterial Hypertension Epidemiology: Romania among the Balkan Countries - Data from SEPHAR Surveys. Medicina Moderna. 2014;21(1):10-16.

4. Dorobantu M, Tautu OF, Dimulescu D, et al - Perspectives on hypertension's prevalence, treatment and control in a high cardiovascular risk East European country: data from the SEPHAR III survey. J Hypertens. 2017. doi:10.1097/HJH.0000000000001572. [Epub ahead of print]

5. Hermida RC, Smolensky MH, Ayala DE, Portaluppi F - Ambulatory blood pressure monitoring (ABPM) as the reference standard for diagnosis of hypertension and assessment of vascular risk in adults. Chronobiol Int. 2015;32(10):1329-1342.

6. Mancia G, Fagard R, Narkiewicz K, et al - 2013 ESH/ESC Guidelines for the management of arterial hypertension: the Task Force for the management of arterial hypertension of the European Society of Hypertension (ESH) and of the European Society of Cardiology (ESC). J. Hypertens. 2013;31:1281-1357.

7. Routledge FS, McFetridge-Durdle JA, Dean CR - Night-time blood pressure patterns and target organ damage: A review. Can J Cardiol. 2007;23(2):132-138.

8. Krzych LJ, Bochenek A - Blood pressure variability: epidemiological and clinical issues. Cardiol J. 2013;20(2):112-120.

9. Birkenhäger AM, van den Meiracker AH. - Causes and consequences of a non-dipping blood pressure profile. Neth J Med. 2007;65(4):127131.

10. Dubielski Z, Zamojski M, Wiechecki B, et al. - The current state of knowledge about the dipping and non-dipping hypertension. Arterial Hypertension. 2016; 20(2):33-43.

11. Letizia C, Ferrari P, Cotesta D, et al. Ambulatory monitoring of blood pressure (AMBP) in patients with primary hyperparathyroidism. J Hum Hypertens 2005;19(11):901-916.

12. Krzyzanowska K, Schnack C, Mittermayer F, et al - High prevalence of abnormal circadian blood pressure regulation and impaired glucose tolerance in adults with hypopituitarism. Exp Clin Endocrinol Diabetes. 2005;113(8):430-434.

13. Pechanova $O$, Paulis $L$, Simko $F$ - Peripheral and central effects of melatonin on blood pressure regulation. Int J Mol Sci 2014;15(10):1792017937.

14. Pietrobelli DJ, Akopian M, Olivieri AO, et al - Altered circadian blood pressure profile in patients with active acromegaly. Relationship with left ventricular mass and hormonal values. J Hum Hypertens. 2001;15(9):601-605.

15. Covic A, Goldsmith DJ, Gusbeth-Tatomir P, et al - What added value does ambulatory blood pressure monitoring brings to the management of post renal transplantation hypertension? Rev Med Chir Soc Med Nat lasi 2003;107(1):89-97.

16. Ohashi N, Isobe S, Ishigaki S, Suzuki T, Motoyama D, Sugiyama T, et al - The effects of unilateral nephrectomy on blood pressure and its circadian rhythm. Intern Med. 2016;55(23):3427-3433.

17. Kario K, Eguchi K, Nakagawa Y, Motai K, Shimada K - Relationship between extreme dippers and orthostatic hypertension in elderly hypertensive patients. Hypertension. 1998;31(1):77-82.

18. Briasoulis A, Silver A, Yano $Y$, Bakris GL - Orthostatic hypotension associated with baroreceptor dysfunction: treatment approaches. J Clin Hypertens (Greenwich). 2014;16:141-148.

19. Mellman TA, Brown DD, Jenifer ES, Hipolito MM, Randall OS Posttraumatic stress disorder and nocturnal blood pressure dipping in young adult African Americans. Psychosom Med. 2009;71(6): 627-630.

20. Huang $Y$, Mai W, Hu Y, et al - Poor sleep quality, stress status, and sympathetic nervous system activation in nondipping hypertension. Blood Press Monit. 2011;16(3):117-123.

21. Xuan AP - Investigate damages in target organs in two groups of patients who have dipper and non-dipper hypertension. J Hypertens. 2011;29:e11.

22. Nesukay $\mathrm{H}$, Polenova $\mathrm{N}$, Titov E-Ambulatory blood pressure monitoring (ABPM) and myocardium deformation parameters in patients with hypertension. J Hypertens. 2016;34:e122-e123.

23. Sousa F, Neves J, Ferreira R, et al. - In hypertension the change from a non-dipper to a dipper pattern is associated with a better cardiovascular 
prognosis than the persistence within the non-dipper pattern. $J$ Hypertens. 2015;33(1):e6.

24. Crippa G, Zabzuni D, Cassi A, Bravi E - Effect of bedtime dosing of barnidipine hydrochloride in non-dipper hypertensive patients with obstructive sleep apnoea not treated with continuous positive airway pressure. Eur Rev Med Pharmacol Sci. 2016;20(2):339-344.

25. Kario K, Nariyama J, Kido H, et al - Effect of a novel calcium channel blocker on abnormal nocturnal blood pressure in hypertensive patients. J Clin Hypertens (Greenwich). 2013;15(7):465-472.

26. Esler M. The sympathetic system and hypertension. Am J Hypertens. 2000;13:99S-105S

27. Dauphinot V, Gosse P, Kossovsky M, et al - Autonomic nervous system activity is independently associated with the risk of shift in the nondipper blood pressure pattern. Hypertens Res. 2010;33:1032-1037.

28. Quijada SG, Sáez MC, Gutiérrez CD, et al - Factores cardiovasculares y hormonales asociados a la falta de descenso nocturno de la presión arterial en sujetos mayores de 55 años. Rev Clin Esp. 2002;202(5):264268.

29. Grassi G, Seravalle G, Quarti-Trevano F, et al - Adrenergic, metabolic, and reflex abnormalities in reverse and extreme dipper hypertensives. Hypertension. 2008;52:925-931.

30. Voichanski S, Grossman C, Leibowitz A, et al - Orthostatic hypotension is associated with nocturnal change in systolic blood pressure. Am J Hypertens. 2012;25(2):159-164.

31. Alquadan KF, Singhania G, Koratala A, Eja AA - Office orthostatic blood pressure measurements and ambulatory blood pressure monitoring in the prediction of autonomic dysfunction. Clin Hypertens. 2017;23:3.

32. Hossain P, Kawar B, El Nahas M- Obesity and diabetes in the developing world - a growing challenge. N Engl J Med 2007;356(3):213-215.

33. Faulkner JL, Bruder-Nascimento T, Belin de Chantemèle EJ - The regulation of aldosterone secretion by leptin: implications in obesityrelated cardiovascular disease. Curr Opin Nephrol Hypertens. 2017;doi:10.1097/MNH.0000000000000384. [Epub ahead of print]

34. Ruano M, Silvestre V, Castro R, et al - Morbid obesity, hypertensive disease and the renin-angiotensin-aldosterone axis. Obes Surg 2005;15:670-676.

35. Westcott KV, Huang BS, Leenen FH - Brain renin-angiotensinaldosterone system and ventricular remodelling after myocardial infarct: a review. Can J Physiol Pharmacol. 2009;87:979-988.

36. Stepniakowski KT, Goodfriend TL, Egan BM - Fatty acids enhance vascular alpha-adrenergic sensitivity. Hypertension. 1995;25:774-778.

37. de Courten M, Zimmet P, Hodge A. et al - Hyperleptinaemia: the missing link in the metabolic syndrome? Diabet Med. 1997;14:200-208.

38. Kang YS - Obesity associated hypertension: new insights into mechanism. Electrolyte Blood Press. 2013;11:46-52.

39. Kanbay M, Turgut F, Uyar ME, et al - Causes and mechanisms of nondipping hypertension. Clin Exp Hypertens. 2008;30:585-597.

40. Fabbian F, Smolensky MH, Tiseo R, Pala M, Manfredini R, Portaluppi F - Dipper and non-dipper blood pressure 24-hour patterns: circadian rhythm-dependent physiologic and pathophysiologic mechanisms. Chronobiol Int. 2013;30(1-2):17-30

41. Ayukusuma AR, Rohman MS, Lukitasari M et al - No difference of serum IL-6 level among dipper and non dipper hypertensive patients. $J$ Hypertens. 2015; doi: 10.1097/01.hjh.0000469858.46811.f4

42. Duggal A, Bal BS, Singh N-Study of dipping and non-dipping patterns in patients of type 2 diabetes mellitus with hypertension and its association with microalbuminuria. Ann Int Med Den Res. 2017;3(2):20-24.

43. Tartan Z, Uyarel H, Kasikcioglu H, et al - Metabolic syndrome as a predictor of non-dipping hypertension. Tohoku J Exp Med. 2006;210:57-66.

44. Tutal E, Sayın B, Ertugrul DT, et al - Is there a link between hyperuricemia, morning blood pressure surge, and non-dipping blood pressure pattern in metabolic syndrome patients? Int J Nephrol Renovasc Dis. 2013;6:71-77.

45. Karaagac $\mathrm{K}$, Tenekecioglu E, Yontar OC, et al - Effect of non-dipper and dipper blood pressure patterns on Tp-Te interval and Tp-Te/QT ratio in patients with metabolic syndrome. Int J Clin Exp Med. 2014;7(5):13971403.

46. Karaagac K, Vatansever $F$, Tenekecioglu E, et al - The relationship between non-dipper blood pressure and thoracic aortic diameter in metabolic syndrome. Eurasian J Med. 2014;46:120-125.

47. Ma Y, Sun S, Peng CK, Fang Y, Thomas RJ - Ambulatory blood pressure monitoring in chinese patients with obstructive sleep apnea. J Clin Sleep Med. 2017;13(3):433-439.

48. Suzuki M, Guilleminault C, Otsuka K, Shiomi T - Blood pressure "dipping" and "non-dipping" in obstructive sleep apnea syndrome patients. Sleep. 1996:19(5):382-387

49. Nabe B, Lies A, Pankow W, Kohl FV, Lohmann FW - Determinants of circadian blood pressure rhythm and blood pressure variability in obstructive sleep apnoea. J Sleep Res. 1995;4(S1):97-101

50. Wolf $\mathrm{J}$, Hering D, Narkiewicz $\mathrm{K}$ - Non-dipping pattern of hypertension and obstructive sleep apnea syndrome. Hypertens Res. 2010;33(9):867871.

51. de Paula Soares CF, Cavichio L, Cahali MB - Lateral pharyngoplasty reduces nocturnal blood pressure in patients with obstructive sleep apnea. Laryngoscope. 2014;124:311-316.

52. Routledge FS, McFetridge-Durdle JA, Dean CR - Stress, menopausal status and nocturnal blood pressure dipping patterns among hypertensive women. Can J Cardiol. 2009;25(6):e157-e163.

53. Refaie WR, Refaie E, Abd El Hady N, et al - Cardiovascular changes in dipper and nondipper hypertension in perimenopausal women (timedependent effects of antihypertensives). Egypt J Int Med. 2012;24(2):3742.

54. Iqbal $\mathrm{A}$, Figenschau $\mathrm{Y}$, Jorde $\mathrm{R}$ - Blood pressure in relation to serum thyrotropin: The Tromsø study. J Hum Hypertens. 2006;20:932-936

55. Canbolat IP, Belen E, Bayyigit A, et al - Evaluation of Daily Blood Pressure Alteration in Subclinical Hypothyroidism. Acta Cardiol Sin. 2017;33(5): 489-494.

56. Kanbay M, Turgut F, Karakurt F, et al - Relation between serum thyroid hormone and 'nondipper' circadian blood pressure variability. Kidney Blood Press Res. 2007; 30(6): 416-420.

57. Kanbay M, Isik B, Akcay A et al - Relation between serum calcium, phosphate, parathyroid hormone and 'nondipper' circadian blood pressure variability profile in patients with normal renal function. Am J Nephrol. 2007;27(5):516-521.

58. Velasquez MT, Beddhu S, Nobakht E, Rahman M, Raj DS - Ambulatory blood pressure in chronic kidney disease: ready for prime time? Kidney Int Rep. 2016;1(2):94-104.

59. Fedecostante M, Spannella F, Cola G, et al - Chronic kidney disease is characterized by "double trouble" higher pulse pressure plus night-time systolic blood pressure and more severe cardiac damage. PLoS One 2014;9(1):e86155.

60. Lurbe $\mathrm{E}$, Redon J, Kesani A, et al - Increase in nocturnal blood pressure and progression to microalbuminuria in type 1 diabetes. N Engl J Med. 2002;347(11):797-805.

61. Sezer S, Karakan S, Çolak T, Haberal M - Nocturnal nondipping hypertension is related to dyslipidemia and increased renal resistivity index in renal transplant patients. Transplant Proc. 2011;43(2):530-532.

62. Wadei HM, Amer H, Griffin MD, Taler SJ, Stegall MD, Textor SC. Abnormal circadian blood pressure pattern 1-year after kidney transplantation is associated with subsequent lower glomerular filtration rate in recipients without rejection. J Am Soc Hypertens. 2011;5(1):39-47.

63. Choudhary L, Gupta P, Gupta A, et al -24 hour ambulatory blood pressure monitoring and left ventricular ejection fraction- prognostic markers in chronic kidney disease. Int J Adv Med. 2016;3(2):402-408.

64. Dziwura J, Bińczak-Kuleta A, Miazgowski T, et al - The associations between G972R polymorphism of the IRS-1 gene, insulin resistance, salt sensitivity and non-dipper hypertension. Hypertens Res. 2011;34:1082-1086.

65. Uzu T, Ishikawa K, Fujii T, et al. - Sodium restriction shifts circadian rhythm of blood pressure from nondipper to dipper in essential hypertension. Circulation, 1997;96:1859-1862.

66. Campese VM, Romoff MS, Levitan D, et al. - Abnormal relationship between sodium intake and sympathetic nervous system activity in saltsensitive patients with essential hypertension. Kidney Int. 1982;21:371378.

67. Piepoli MF, Hoes AW, Agewall S, et al - 2016 European Guidelines on cardiovascular disease prevention in clinical practice. Eur Heart J. 2016;37:2315-2381.

68. Chen Y, Liu JH, Zhen Z, et al. - Assessment of left ventricular function and peripheral vascular arterial stiffness in patients with dipper and nondipper hypertension. J Investig Med. 2017; pii: jim-2017-000513

69. Mahabala C, Kamath P, Bhaskaran U, et al - Antihypertensive therapy: nocturnal dippers and nondippers. Do we treat them differently? Vasc Health Risk Manag. 2013;9:125-133.

70. Kario K, Schwartz JE, Pickering TG - Changes of nocturnal blood pressure dipping status in hypertensives by nighttime dosing of alpha-adrenergic blocker, doxazosin: results from the HALT study. Hypertension. 2000;35(3):787-794.

71. Wang $\mathrm{C}, \mathrm{Ye} \mathrm{Y}$, Liu $\mathrm{C}$, et al - Evening versus morning dosing regimen drug therapy for chronic kidney disease patients with hypertension in blood pressure patterns: a systematic review and meta-analysis. Intern Med J. 2017;47(8):900-906. 
72. Wang C, Zhang J, Liu X, et al - Effect of Valsartan with bedtime dosing on chronic kidney disease patients with nondipping blood pressure pattern. J Clin Hypertens (Greenwich). 2013;15(1):48-54.

73. Fukuda M, Kimura G. Salt sensitivity and nondippers in chronic kidney disease. Curr Hypertens Rep. 2012;14(5):382-387.

74. Tosu AR, Demir S, Selcuk M, et al-Comparison of inflammatory markers in non-dipper hypertension vs. dipper hypertension and in normotensive individuals: uric acid, C-reactive protein and red blood cell distribution width readings. Postepy Kardiologii Interwencyjnej. 2014;10(2):98-103.

75. Buyukkaya E, Erayman A, Karakas E, et al - Relation of red cell distribution width with dipper and non-dipper hypertension. Medicinski Glasnik. 2016;13(2):75-81.

76. Kaya MG, Yarlioglues M, Gunebakmaz O, et al. - Platelet activation and inflammatory response in patients with non-dipper hypertension. Atherosclerosis. 2010;209(1):278-282

77. Ortakoyluoglu A, Boz B, Sitki DO, et al - The association of serum gamma-glutamyl transpeptidase level and other laboratory parameters with blood pressure in hypertensive patients under ambulatory blood pressure monitoring. Ther Clin Risk Manag. 2016;12:1395-1401.

78. Tabara $\mathrm{Y}$, Igaseb $\mathrm{M}$, Mikia $\mathrm{T}$, et al - B-type natriuretic peptide is a determinant of the nocturnal increase in blood pressure independently of arterial hypertrophy and hypoxia. J Hypertens. 2016;34:2393-2401.

79. Bakirci EM, Degirmenci $\mathrm{H}$, Hamur $\mathrm{H}$, et al. - New inflammatory markers for prediction of non-dipper blood pressure pattern in patients with essential hypertension: Serum YKL-40/Chitinase 3-like protein 1 levels and echocardiographic epicardial adipose tissue thickness. Clin Exp Hypertens. 2015;37:1-6.

80. Ji Q, Cheng G, Ma N, et al - Circulating Th1, Th2, and Th17 levels in hypertensive patients. Dis Markers. 2017; 7146290

81. Kadoya M, Koyama H, Kanzaki A, et al - Plasma brain-derived neurotrophic factor and reverse dipping pattern of nocturnal blood pressure in patients with cardiovascular risk factors. PLoS One. 2014;9(8): e105977.

82. Meric M, Soylu K, Avci B, et al - Evaluation of plasma chemerin levels in patients with non-dipper blood pressure patterns. Med Sci Monit. 2014;20:698-705.

83. Zheng $\mathrm{H}$, Xie $\mathrm{X}$, Xie $\mathrm{N}, \mathrm{XuH}$, et al - Sphingomyelin levels in nondipper and dipper hypertensive patients. Exp Ther Med. 2014;7:599-603.

84. Cayli M, Gur M, Elbasan Z, et al - High-Sensitivity Cardiac Troponin T Predicts Nondipper Hypertension in Newly Diagnosed Hypertensive Patients. J Clin Hypertens (Greenwich). 2013;15(10):731-736. 